\title{
La Parra, Emilio y Mà Àngeles Casado: La Inquisición en España. Agonía y abolición
}

\author{
Madrid, Los Libros de la Catarata, 2013, 222 páginas
}

Suele suceder que los buenos libros se sirven en formato modesto, manejable, de bolsillo. Como este que, me apresuro a decir, es excelente pues en él se marida el rigor histórico con una prosa pulcra y didáctica. Resulta, además, muy oportuno para los tiempos que corren pues en sus páginas se retrata la realidad de un país que, durante siglos, estuvo sometido a la siniestra actividad de quienes rigieron esa tétrica y represora institución conocida como Tribunal del Santo Oficio o, más comúnmente, Inquisición.

Vaya por delante que este no es un estudio al uso y así lo advierten, asimismo, los autores. Sobre la Inquisición se ha escrito mucho desde que Juan Antonio Llorente aprovechara su abolición, decretada por Napoleón en Chamartín a primeros de diciembre de 1812, así como la ocupación de su sede central en Madrid para acopiar, por indicación de José I, un gran caudal de información que le permitió escribir su Memoria Histórica (1812) y, más tarde, su Historia de la Inquisición. No haré referencia alguna a la bibliografía generada hasta hoy, pues el lector encontrará en las páginas finales del libro las entradas fundamentales precedidas de una nota crítica que, en sí misma, constituye un modelo de síntesis y precisión. Asimismo los autores transcriben las fuentes imprescindibles (aunque a lo largo del libro haya abundantes alusiones y citas textuales) sobre cuyo análisis sustentan su argumentación.

Emilio La Parra y Ma Ángeles Casado formulan los objetivos que persiguen de manera muy sencilla; otra cosa es la complejidad que los mismos entrañan. Plantean cubrir un vacío historiográfico y responder a una pregunta (o varias). La historiografía no había resuelto satisfactoriamente a día de hoy cómo fueron los años finales del Santo Oficio, si fue capaz de mantener sus habituales pautas de comportamiento y de qué manera le afectó la coyuntura política de finales del siglo XVIII y principios del XIX. Pero a ese vacío se le añade, cuanto menos, un interrogante: ¿por qué, y cómo, resistió tanto la Inquisición española?, ¿qué puede justificarlo? Y los autores responden, con solvencia, a estas cuestiones en un estudio bien estructurado, metódicamente desarrollado, nutrido de ejemplos reveladores de cada circunstancia y con una adecua- 
da contextualización que, a la postre, satisface plenamente al lector pues le descubre una realidad ignorada hasta la fecha.

Entre 1746 y 1785 la Inquisición fue desapareciendo de buena parte de los Estados europeos en los que había sido instaurada en épocas pasadas: Nápoles, Parma, Milán, Toscana, Módena... A principios del siglo XIX fue abolida en Portugal y en España perviviría todavía unos cuantos años, permaneciendo incólume y muy activa a día de hoy la Inquisición Pontificia, y aunque haya trocado su nombre por el de Congregación para la Doctrina de la Fe sus objetivos no han cambiado pese a la aparente suavización de las formas.

Este tribunal mixto, papal y real, hunde sus raíces en el siglo XIII aunque en España comenzó a actuar en Castilla allá por 1478 tras autorizar Sixto IV a los Reyes Católicos el nombramiento de inquisidores para perseguir a conversos judaizantes. Dependiente de la Corona de Castilla se instalaría en la de Aragón, no sin fuertes tensiones, entre 1484 y 1488. Auténtico símbolo del Antiguo Régimen, la Inquisición se integró a la perfección en el paisaje político-administrativo y religioso de la monarquía hispánica mostrando gran capacidad para adaptarse a tiempos y circunstancias muy diversas, modificando su objeto primigenio de persecución y convirtiéndose en una eficaz arma para vigilar la ortodoxia religiosa y las costumbres de los españoles. Por ello era tan odiada como temida.

Si la Inquisición contó con decididos opositores durante el siglo XVIII (los ilustrados), si fue capaz de disputar la autoridad a los propios monarcas de la Ilustración, si poderosos personajes (caso de Godoy) que llegaron a gozar de un poder casi omnímodo tuvieron en su mano liquidarla (y no lo hicieron), si los propios liberales (con todo a su favor) se mostraron un tanto remisos a darle la puntilla aprovechando la primera gran estocada de muerte propinada por Napoleón, si.... ¿Cómo explicar su larga pervivencia? Para responder, los autores se alinean desde el principio con los argumentos defendidos desde tiempo atrás por el profesor Gérard Dufour.

La institución - una auténtica «bicha»- resistía - o aparentaba resistir-gracias a que disponía de suficiente cobijo y protección. ¿De índole política o social? La respuesta de La Parra y Casado es negativa, inclinándose por la de carácter cultural. El continuismo, la supervivencia, de la Inquisición fue posible porque España era un país confesionalmente católico, la cultura dominante era la católica y, por si hubiera alguna duda, así lo reconoció la propia constitución gaditana. Los españoles, por tanto, estaban impregnados de ese pálpito inquisitorial que, inmersos ya en el siglo XXI, aún no nos ha abandonado. Sólo basta con escuchar algún que otro exabrupto lanzado desde las ondas o leer algunas de las soflamas aparecidas en ciertos medios de comunicación para comprobarlo. Por eso el libro es actual. En el imaginario español está firmemente arraigada la figura del inquisidor $y$, sobre todo, los métodos que empleaban los «funcionarios» del Tribunal: intolerancia, delación, secreto, tortura, escarnio, castigo público, muerte....

El libro descubre los avatares padecidos por quienes pusieron su empeño en suprimir la Inquisición, en las presiones de todo tipo ejercidas por sus partidarios y detractores. Desvela las estrategias desplegadas, por ejemplo, por la Nunciatura en connivencia 
con las fuerzas más reaccionarias; el papel de los políticos liberales más caracterizados (Argüelles, Mexía Lequerica), las esperanzas y zozobras de un período ilusionante que encarnaron los debates en las Cortes gaditanas en los que los liberales pretendieron vaciar de contenido el Tribunal después de que Napoleón decretara su abolición. Antes hubo políticos que se la jugaron y perdieron, como Jovellanos o Urquijo. Y gentes de a pie que murieron víctimas de la ferocidad inquisitorial, como María Dolores López, mujer de condición social baja y carne de sus confesores, ajusticiada en Sevilla en 1781. Fue la última víctima del XVIII; aunque no escaparon de sus garras intelectuales (Bails, Samaniego, Iriarte, Ramón de Salas), prelados (Tavira o Palafox), ni siquiera nobles como la condesa de Montijo.

¿Por qué no fue suficiente una sola abolición? La respuesta está en este libro. Los años que mediaron entre 1808 y 1834 fueron enormemente complejos. Y las disputas ideológicas, aderezadas con argumentos jurídicos y religiosos, dejaron un reguero de damnificados. Es cierto que la libertad de imprenta, aprobada el 10 de noviembre de 1810, asestó un duro golpe a la Inquisición al permitir que frente a la censura (poderosa arma inquisitorial) se alzara la libertad de opinión propiciando un gran salto cualitativo de claros tintes revolucionarios. El estudio que desarrollan los autores en torno al debate parlamentario que se generó sobre la Inquisición es espléndido y revelador, resultando fundamental para entender el resto del proceso histórico. Un proceso lleno de paradojas en el que quedó bien manifiesto (por si no lo estuviera ya) que la Inquisición era un instrumento político enormemente eficaz en manos del poder. Y aunque las Cortes aprobaran el 22 de enero de 1813 que este Tribunal resultaba incompatible con la Constitución y, apenas un mes más tarde lo abolían, a la vez creaban los denominados Tribunales Protectores de la Fe. La pugna entre el poder civil y el eclesiástico se saldaba con la victoria del primero que prácticamente liquidaba el Santo Oficio. Y así lo entendieron los propios contemporáneos.

Tras regresar del exilio francés la actitud de Fernando VII es bien conocida y el libro evidencia, por si hubiere alguna duda, la catadura moral del «deseado» monarca. Le faltó tiempo para borrar de un plumazo los logros gaditanos, declarando nulas las disposiciones de las Cortes y reinstaurando el absolutismo. Y con ello, la Inquisición, por decreto de 21 de julio de 1814, cobraba nuevo vigor tanto desde el punto de vista religioso como político. Emilio La Parra y Ma Ángeles Casado desgranan los avatares sociopolíticos vividos en España hasta la década de los treinta, desvelando el lánguido transitar de la Inquisición en un país en el que otras instituciones creadas por el poder civil (la policía) comenzaban a desarrollar funciones otrora cumplidas por ella. Tras el pronunciamiento de Riego la Inquisición fue de nuevo abolida y los presos políticos liberados en marzo de $1820 \mathrm{y}$, pese a la restauración absolutista propiciada por la entrada en España en abril de 1823 de los Cien Mil Hijos de San Luis, Fernando VII no llegó a restablecer el Tribunal. Es cierto que los tiempos estaban cambiando y que estas instituciones arcaicas encajaban mal en la Europa del momento, pero España era diferente y alumbró las denominadas Juntas o Tribunales de Fe que, auspiciadas por una jerarquía eclesiástica intolerante ante las desviaciones del catolicismo, tenían entre sus objetivos controlar las conciencias y erradicar cualquier signo de heterodoxia religiosa 
o política. No duraron mucho, pero la de Valencia ostenta el lamentable privilegio de haber dictado la última condena a muerte de una persona por delito de herejía, en este caso un maestro de nombre Cayetano Ripoll. No fue la Inquisición, claro; pero sí un tribunal que habría gustado de serlo.

La supresión definitiva llegaría a mediados de julio de 1834 cuando la reina regente puso su firma al decreto elaborado por Nicolás María Garelli, ministro de Gracia y Justicia, que de manera taxativa abolía el Santo Oficio. Y hasta hoy. Pero como decía Mariano José de Larra, y recogen los autores, «las costumbres no se varían en un día (...) ni con un decreto, y desgraciadamente un pueblo no es verdaderamente libre mientras que la libertad no esté arraigada en sus costumbres e identificada con ellas». Esta es la cuestión. Por si todavía alguien abriga dudas acerca de la importancia de la educación para formar los tan necesarios ciudadanos libres. Porque restan todavía inquisidores a la vuelta de cada esquina; quizá hayan cambiado su porte pero no sus intenciones ni su «cultura»; esa que, como se encargan de hacernos comprender los profesores La Parra y Casado, dominaba en el Antiguo Régimen y procuró la supervivencia del siniestro tribunal. Conviene, por tanto, leer este libro. No defrauda. En absoluto.

Armando Alberola Romá

Universidad de Alicante 